\title{
AI technology and online purchase intention: Multi-group analysis based on perceived value
}

\author{
Jiwang Yin ${ }^{1}$, Xiaodong Qiu ${ }^{2}$ and Xiaodong Qiu * \\ Beijing Jiaotong University ; $18612634532 @ 163 . c o m$ \\ 2 Beijing Jiaotong University ; qiuxd08@126.com \\ * Correspondence: qiuxd08@126.com; Tel.:13601352181
}

\begin{abstract}
Background: AI technology has been deeply applied to online shopping platform to provide more accurate and personalized services for consumers. It is of great significance to study the different functional experience of AI for consumers to improve the current application status of AI technology.(2)Method: Based on the "S-O-R" model, this study divided the AI technology experienced by the consumers of online shopping platform into accuracy, insight and interaction experience. Takes the perceived value as the mediating variable from the prospect of perceived utility value and perceived hedonic value. This article use empirical research method to analyze the effect of three dimensions of online shopping AI experience to research the internal influence mechanism of consumers purchase intention. (3) Results:1) The accuracy, insight and interaction experience of AI marketing technology have a significant positive impact on consumers' perceived utility value and hedonic value respectively; (2)Both of the perceived utility value and perceived hedonic value obtained by AI technology experience can promote the formation of consumers' purchase intention; (3) The perceived hedonic value was better than perceived utility value to promote the consumers' purchase intention; (4)The results of multi group analysis show that some younger and less experiences consumers groups prefer the pleasure experience such as shopping desire stimulation, shopping process relaxation and pleasure that AI marketing brought. However, utilitarian value cannot promote this kind of consumers' purchase intention. (4) Conclusions: Perceived utility value and perceived hedonic value can be the intermediary between AI technology and consumers' purchase intention.
\end{abstract}

Keywords: Artificial Intelligence Marketing; Online shopping; Perceived Utility Value; Perceived Hedonic Value; Purchase Intention; S-O-R

\section{Introduction}

As an important branch of computer science, artificial intelligence (AI) makes use of artificial methods and technologies to make automatic machines and computers simulate, extend and expand human intelligence, so that some machines and equipment can have human thinking ability-- like self-learning, self-programming and automatic mental labor [1]. After its birth and industrialization stage, AI has finally ushered in an explosive development in the world with the application of big data after 2000. With the rapid development of the new generation of information technology and the popularization of marketing applications, marketing has experienced from one-way marketing of Web1.0 to interactive marketing of Web2.0, then to precision marketing based on big data, and the smart marketing stage supported by AI technology [2]. AI technology can enhance the interaction not only among customers, products or services, but also interactive environment, and match demands quickly [3]. AI chat robots, content recommendation systems, 
and consumer feature recognition become artificial agents for AI marketing activities [4]. Amazon takes the lead in using artificial intelligence technology to achieve the retail relocation of people, goods and stores, and extends its artificial intelligence framework DSSTNE from dialogue, language understanding and object recognition to the field of search and recommendation, makes the recommendation of related products and complementary products more personalized and real-time, improves the conversion rate of product purchase and realizes precision marketing [5].

Capgemini Digital Transformation Research Institute released the report《Secrets of Artificial Intelligence Winning Consumers: Enabling Human Intelligence》.According to the research report, 38\% of consumers have a good AI experience and their purchase volume will increase significantly. However, some scholars only from the qualitative point of view to illustrate that AI marketing technology can bring utility and value to consumers, then promoting the formation of purchase intention and realizing the growth of sales revenue. What kind of internal mechanism does AI technology affect consumers' purchase intention? Whether AI technology can be used as a stimulus to extend the boundary of technology acceptance model is still a blank.

In this view, through the establishment of structural equation model, this study explores the relationship between AI technology of online shopping platform and consumers' purchase intention, analyzes the mediating role of perceived hedonic value and perceived utilitarian value. It provides a realistic basis for enterprises to provide customized services with more personalized preferences in the face of consumers with different sample characteristics.

\section{Review of related research}

\subsection{SOR model}

Stimulus-Organism-Response (SOR) model was first proposed by Mehrabian and Russell in 1974 [6]. It is considered that the assessment process of human body is different from that of machine. Various stimuli in the environment (S), such as auditory, visual and olfactory stimuli will cause changes in the state of internal emotion and cognitive mechanism $(\mathrm{O})$ and then cause the response $(\mathrm{R})$. (Figure 1)

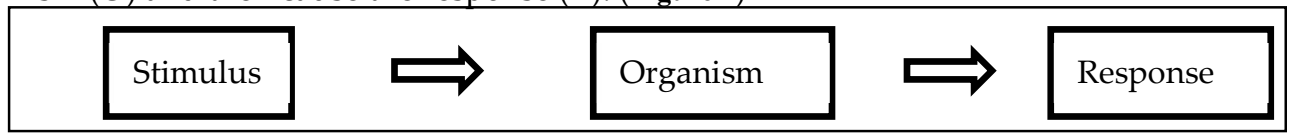

Figure 1 Mehrabian-Russell S-O-R model

Donovan and Rossiter [7] first applied the SOR model to the shopping field. Eroglua et al. [8] introduced SOR model into online shopping platform for the first time to explore the atmosphere of online stores and explore the influence of online shopping consumption behavior through the intervention of preference and cognitive state.

The research on the purchase intention of online shopping platform using SOR model mainly includes the following points: From the perspective of website atmosphere of online shopping platform perception brought by the internal state atmosphere of the website will have an impact on the consumers' approach or avoidance behavior [9] .The website image (security, convenience, entertainment) will affect the perceived quality and purchase of online stores intention [10]. The state of consumers after feeling (pleasure and impulse) also affects consumers' consumption impulse and expenditure [11]. Website navigation structure affects purchase intention through consumer participation, website atmosphere acceptance and risk acceptance [12]. Sanjeev Prasha et al. [13] maintain that the website atmosphere is composed of internal factors (hedonic shopping value and utilitarian shopping value) ,external factors (website information, website entertainment and effectiveness of information content) and the satisfaction brought by websites to consumers will directly affect consumers' consumption behavior. From the perspective of e-commerce services, Zhang Beijia [14] takes the ease of online return policy as a stimulus variable and has a positive impact on consumers' purchase intention through the intermediary 
effect of perceived commodity quality, while perceived shopping risk cannot be used as an intermediary variable to influence consumers' purchase intention. From the perspective of e-commerce platform reputation and image, it is found that reputation has a positive correlation with online repurchase intention, perceived risk has a negative impact on online repurchase behavior and subjective norms have a positive impact on consumers' purchase intention [15]. Online store image can influence consumers' online purchasing behavior through consumer interest [16], perceived value and flow experience [17].

The current research on technology as stimulus is mainly reflected in the navigation structure of the website [12], the implementation of platform assisted business technology and the effectiveness of the network [18]. At present, AI technology, which has industry empowerment significance, as a kind of stimulation, has no quantitative research on the impact on consumers' internal mechanism on purchase intention.

\subsection{AI technology experience of online shopping platform}

Based on a large number of existing literature on AI marketing at home and abroad and the practice of industrial workers, this study concludes that the AI technology experience of online shopping platform for consumers can bring consumers intuitive AI experience through intelligent identification and search, intelligent recommendation and virtual customer service assistant. Therefore, this study innovatively takes the above three types of AI applications for online consumers corresponding experience effects--accuracy experience, insight experience and interactive experience.

\subsubsection{Accuracy experience}

The integration of artificial intelligence, information technology and systems engineering related technologies forms an intelligent decision support system, which can change the potential of human decision-making [19]. Intelligent recognition and search refers to the use of big data and AI technology by the marketing engine of e-commerce platform to help consumers realize rapid screening in massive data. When consumers input keywords, voice or pictures in the search bar, AI can use text, voice and image analysis technology to identify problems and search to find possible targeted commodity and prioritized [20]. Autonomous learning neural network reduces the error rate of image recognition from 30\% in 2010 to 4\% in 2016 [21]. In 2019, iFLYTEK's speech recognition rate has reached $98 \%$, and it is predicted that AI speech recognition will reach the same level as human beings in 2021. The increase of data volume leads to the complexity of individual decision-making and make the decision-making process impossible to complete. Intelligent search engine can help users extract noise and help consumers accurately find the target commodity. The above fully reflects that AI technology can bring accuracy experiences to consumers. At present, Chinese leading online shopping platforms such as Taobao, Jingdong, Pinduoduo and other search engines have been able to realize the recognition of text, picture and voice.

\subsubsection{Insight experience}

Machine learning can customize the content of the company's website to achieve the consistency of user preferences and willingness to pay, and connect customers in all channels and devices in a seamless and personalized way. It can be said that machine learning is the best technology for understanding consumer preferences [22]. AI can realize accurate prediction of user needs, insight into user signs, and provide personalized solutions [23].The marketing software system applying big data and AI technology is an interactive consultation and decision-making system [24]. Its most obvious feature is automatic knowledge discovery and intelligent decision-making [25]. From the perspective of users, the primary application of AI in marketing field is to form precision marketing on demand for thousands of people [26], and the most common application is the personalized recommendation system [27], such as the intelligent push part of "guess you like" of the online shopping platform. AI marketing technology makes full use of the large amount of data retained in the e-commerce platform to realize information insight into consumer 
behavior [28]. It uses the recommendation engine to recommend products that may be purchased in the future according to the past purchased behavior of users, reduces the cognitive load of consumers, and is committed to providing optimal services for consumers through prediction [21]. The accuracy and effect of "intelligent" advertising carried out by AI technology are more significant than those of traditional retail [28]. The above reflects the insight function experience that AI marketing technology brings to consumers.

\subsubsection{Interactive experience}

Natural language interaction and machine learning technology make AI customer service replace artificial customer service, which can understand consumer language and reply [24], provide users with a communication mode similar to that between people [29], help enterprises carry out member marketing and sales services, and record customer behaviors and preferences, so as to adapt to different customers. The virtual assistant of online shopping platform has begun to play the role of intelligent customer service, and has been deeply applied in the communication between consumers and merchants, especially in the scene of consulting common questions such as products, inventory, invoice, logistics, return, etc. Amazon, Jingdong, Alibaba and other e-commerce platforms have developed smart speakers such as Echo,Dingdong and Tmall genie. As the entrance, AI virtual assistant can assist consumers to make complex purchase decisions, complete closed-loop consumption and bring intelligent interactive experience to users through voice interaction with consumers. The above fully reflects the interactive experience that AI marketing technology brings to consumers.

\subsection{Consumer perceived value}

Consumer perceived value refers to the overall evaluation of perceived differences that consumers pay and obtain in the process of shopping [30]. In the process of explaining consumer behavior, multi-dimensional perceived value survey can more specifically explain the impact of different consumption scenarios on consumers' wishes than one-dimensional structure, and some of the dimensions of perceived value research are embodied in the perception of commodity attributes [31], perception of cost [32], convenience perception [33], interactive relative preference experience perception [34], brand value perception [35] and consumer lifetime value perception [36], etc. Some scholars also summarized consumer perceived value as perceived utility value, perceived hedonic value, perceived social value and perceived cognitive value [37].

On the research of consumer perceived value in the use of technology systems, the technology acceptance model (TAM) proposed by Davis [38] in 1989 sets perceived ease of use and perceived usefulness as independent variables, considers that perceived usefulness (system helps improve work performance) and perceived ease of use (convenience of system use) will affect users' attitude towards technology use, and then affect their behavior. It is believed that users' use of technological ways is influenced by their purposes and intentions. Subsequently, Davis proposed that perceived usefulness has a greater impact on users' decision to use the system than perceived ease of use [39]. In the study of consumer behavior in the context of internet technology, Moon and Kim extended TAM, and proposed that the interest of websites (the sense of concentration, novelty seeking and pleasure) is also an important factor affecting consumers' perceived value [40]. Yang \& Lin decomposed the perceived value dimension of online social platform into hedonic value, social value and cognitive value, and evaluated the mediating role of consumers in using social platform [41]. Chu Tanming divides perceived value into three dimensions: perceived utilitarian value, perceived hedonic value and perceived social value as mediators, verifying that it has a significant impact on consumers' online shopping channel choice intention [42]. Sang Jon Ahn divided consumer perception into perceived convenience value, perceived emotional value and perceived use value to evaluate customer acceptance of online banking [43]. I Gusti N.M.W.A concluded that perceived utilitarianism and perceived hedonism play a promoting role in the influence of consumers' online second purchase intention [44]. 
Perceived utilitarian value is usually defined as the utility related value embodiment of behavior or product itself [39], saving of shopping and time cost [32] and convenience of use [33-34]. Perceived hedonic value is defined as pleasure, relaxation [43], arousal, curiosity and surprise [41-42], and mental concentration and interest in interactive process degree [41]. The reason why the marketing scene of online shopping platform can take the lead in the application of AI technology is mainly because the e-commerce platform has accumulated a large number of consumer behavior data, including browsing records, consumer characteristics, etc. AI technology can continuously self-study, algorithm iteration, directly bring consumers the practical value of analysis and recommendation and rapid change of visual stimulation. Therefore, the perceived value of AI technology in online shopping can be measured by perceived utility value and perceived hedonic value.

\section{Conceptual model and research hypothesis}

\subsection{Model framework}

Based on the analysis of the above literature research results, this study draws on the SO-R model research framework, takes the online shopping platform AI marketing technology experience as the stimulus, the consumer perceived value as the emotional mechanism, and the consumer purchase intention as the response result. Based on the above views, the theoretical model shown in Figure 1 is obtained. As the antecedent variable, the online shopping platform AI marketing experience is divided into three dimensions: accuracy experience, insight experience, interactive experience; consumption .As an intermediary variable, consumer perceived value can be divided into perceived utilitarian value and perceived hedonic value; consumer purchase intention is taken as the result variable.

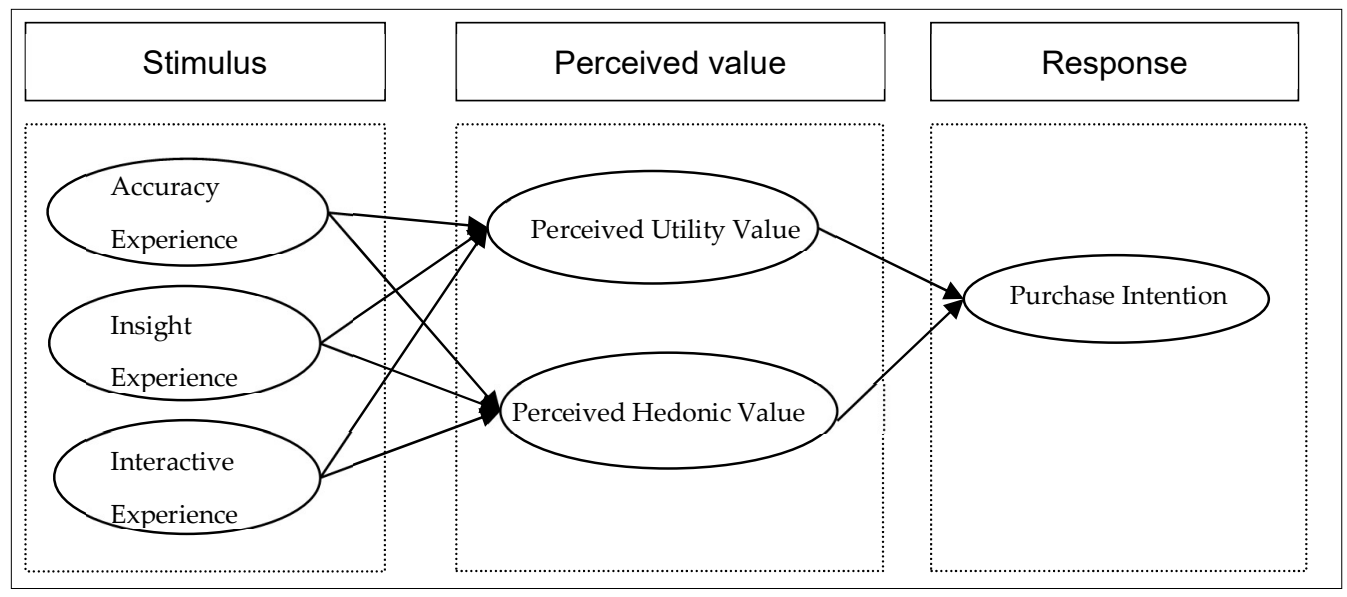

Figure 2 Theoretical Model Framework

\subsection{Research hypothesis}

3.2.1 AI marketing technology experience and consumer perceived value of online shopping platform

The stimulation of AI marketing technology is conducive to consumers to make complex purchase decisions [29], which can save the time and cost of shopping for consumers [30], making shopping choices more accurate and more conducive to the improvement of consumers' shopping efficiency [45]. The use of artificial intelligence technologies such as visual recognition, speech recognition and machine vision can better insight into consumer behavior from five aspects: problem recognition, information collection, alternative evaluation, purchase decision-making and post purchase evaluation [46], so as to provide consumers with more efficient consumption reference and make the value perception 
form of the whole consumption process more rich and smooth. In the process of interaction with e-commerce platform, accurate and extended information stimulation can expand the boundary of consumers' target selection. The visual impact of online shopping and surfing can meet the pleasure, respect and attention of consumers' personalized customized information needs. Through machine vision and deep learning technology, artificial intelligence can search for words, pictures and voice, so that consumers can accurately identify product features, thus enriching the consumer search experience, saving consumers' shopping time, reducing the boredom in the shopping process and increasing the interest of the consumption process [47]. Therefore, the following assumptions are put forward:

H1a: The improvement of accuracy experience of AI marketing technology in online shopping platform is conducive to promoting the formation of consumers' perceived utility value.

H1b: The improvement of accuracy experience of AI marketing technology in online shopping platform is conducive to enhance the formation of consumers' perceived hedonic value.

Machine learning is an important branch of artificial intelligence. According to the algorithm of evolutionary behavior based on empirical data, it can accurately observe customers' preferences and shopping needs, push personalized information for existing and potential customers and provide more effective purchase suggestions for consumers [48]. But the intelligent push of information need to influence consumers' purchasing behavior through some mechanism. The pushed information must make consumers perceive the utility and effectiveness of the information, or bring a certain degree of participation and enjoyment of physical and mental pleasure in the shopping process, otherwise the purpose and significance of shopping will be lost [49]. Therefore, the following assumptions are put forward:

H1c: The improvement of insight experience of AI marketing technology in online shopping platform is conducive to promoting the formation of consumers' perceived utility value.

H1d: The improvement of insight experience of AI marketing technology in online shopping platform is conducive to promoting the formation of consumers' perceived hedonic value.

People can have some positive or negative emotional connection and influence with the power brought by artificial intelligence, even if people know that this power is not the real emotional interaction between people [50]. According to the analysis of the application status of Jingdong AI robot, some scholars believe that AI technology can help consumers' feedback management automation and emotional analysis driven by artificial intelligence can help marketers better respond to consumers, make robot customer service on e-commerce platform have better intelligence quotient and bring better consumer value experience for consumers' online shopping [2]. Therefore, the following assumptions are put forward:

H1e:The improvement of interactive experience of AI marketing technology in online shopping platform is conducive to promoting the formation of consumers' perceived utility value.

H1f: The improvement of interactive experience of AI marketing technology in online shopping platform is conducive to promoting the formation of consumers' perceived hedonic value.

3.2.2 Perceived value and purchase intention of online consumers

Empirical studies have confirmed that the perceived value of online store image in online shopping environment can bring about purposeful and impulsive buying behavior [17]. A large number of studies have shown that purchase intention is based on the symbolic and functional attributes of the product, while the utilitarian value is reflected in the practicality, convenience and cost saving experienced by consumers in the shopping process [51-53]; utilitarian value will play a role when consumers only focus on the visible 
benefits of the product itself and influence consumers to choose goods according to their own needs In the process of online shopping[54]; the utilitarian value brought by the convenience of technology and the improvement of shopping efficiency can improve consumer satisfaction, enhance consumption desire and promote re consumption [55]. Perceived hedonic value refers to the subjective experience of pleasure, interest and relaxation obtained by consumers in the process of shopping. The pleasure of consumption process can have a positive impact on impulse consumption intention. The perceived function value and perceived hedonic value of consumption process are conducive to the occurrence of online repurchase behavior [56]. Artificial intelligence makes marketing more intelligent, more efficient, more conducive to consumer decision-making, and can obtain better marketing effect. Therefore, the following assumptions are put forward:

H2a: The perceived utility value brought by AI marketing technology experience of online shopping platform can promote consumers' purchase intention.

$\mathrm{H} 2 \mathrm{~b}$ : The perceived hedonic value brought by AI marketing technology experience of online shopping platform can promote consumers' purchase intention.

\section{Research design}

\subsection{Scale Design}

As for the measurement of AI marketing technology experience of online shopping platform, there is no mature measurement scale, which belongs to the innovative research in this field. The measurement of AI marketing technology experience is mainly through the comprehensive research of the following information: 1) literature review of current AI marketing technology experience research; 2) actual functional scenarios of AI marketing of China's top three e-commerce platforms; 3 ) industrial workers' working judgment on the impact of consumer behavior by using AI marketing; 4) marketing experts' opinions. Through the summary of the above information, this paper measures the consumers' AI marketing technology experience of online shopping platform from three dimensions of accuracy, insight and interactivity. The measurement of accuracy experience comes from the online shopping websites of "Taobao", "Jingdong" and "Pinduoduo", which are the top three e-commerce websites in China in 2019, to explore their AI marketing search engine for consumers and to measure the accuracy of the retrieval target by using three ways of input text, picture and voice. The measurement of insight experience refers to the research viewpoints of V. Kumar et al. [21], Jordan \& Mitchell [22], Qian Minghui [23] which designs the scale combining with the relevant functions of the above online shopping platform AI marketing recommendation. The measurement of interactivity refers to the responsiveness measurement dimension of Jiang Shen [57] online interaction, and fully combines the above e-commerce platform artificial intelligence customer service function to design the scale.

The perceived utility value refers to the scale of Chu Tanming [42] and modified according to the characteristics of AI technology experience. The scales of Moon \& Kim [40] and Yang \& Lin [41] were used to evaluate the perceived hedonic value. The consumers purchase intention were refers to the scale of Carlota LR et al. [56].

According to the measurement items of the above scale, the questionnaire was compiled with Likert scale 5 which point 1 indicated very disapproval and point 5 indicated strongly approval. Three e-commerce industry experts and two e-commerce enterprise executives were invited to review and revise the questionnaire to form the draft of the questionnaire. In order to ensure the rationality and effectiveness of the questionnaire design, the survey was completed in two stages. First of all, the pre survey stage. We use the questionnaire star platform to make the questionnaire and forward it to 50 people through Wechat to fill in the questionnaire. We eliminated the questionnaire that took less than 60 seconds to reduce the probability of random filling in. Finally, 43 valid questionnaires were confirmed, and the effective rate was $86 \%$. Exploratory factor analysis was carried out for the questionnaire in the pre survey stage. Through the test of 50 small-scale questionnaires, 6 latent variables and 23 questions were obtained. The $\alpha$ value of the related 
variables is 0.97 , which is greater than 0.9 , so the questionnaire has good reliability and can be used for formal research.

The main body of the questionnaire is divided into two parts: the first part is the statistics of personal basic information and the second part is the measurement of six latent variables (Table 1).

Table 1. Questionnaire scale.

\begin{tabular}{|c|c|c|}
\hline Latent variable name & Code & Measurement item \\
\hline \multirow{4}{*}{ Accuracy (AC) } & $\mathrm{AC} 1$ & $\begin{array}{l}\text { When I shop online, AI marketing technology can help } \\
\text { me accurately retrieve the goods I want by inputting } \\
\text { words. }\end{array}$ \\
\hline & $\mathrm{AC} 2$ & $\begin{array}{l}\text { When I shop online, AI marketing technology can help } \\
\text { me accurately retrieve the goods I want by inputting pic- } \\
\text { tures. }\end{array}$ \\
\hline & AC3 & $\begin{array}{l}\text { When I shop online, AI marketing technology can help } \\
\text { me accurately retrieve the goods I want by inputting } \\
\text { voice. }\end{array}$ \\
\hline & IS1 & $\begin{array}{l}\text { When I shop online, AI marketing technology can recom- } \\
\text { mend what I want based on my browsing habits. }\end{array}$ \\
\hline \multirow[t]{2}{*}{ Insight（IS） } & IS2 & $\begin{array}{l}\text { When I shop online, AI marketing technology can pro- } \\
\text { vide (personalized) user shopping interface in line with } \\
\text { my preferences according to my information (browsing } \\
\text { habits, registration information, shopping history). }\end{array}$ \\
\hline & IS3 & $\begin{array}{l}\text { When I shop online, the "read and see", "guess what you } \\
\text { like" and "recommend for you" section on the platform } \\
\text { can provide the goods I may buy. }\end{array}$ \\
\hline \multirow{4}{*}{ Interactivity（IT） } & IT1 & $\begin{array}{l}\text { When I shop online, the AI virtual customer service as- } \\
\text { sistant can answer my questions. }\end{array}$ \\
\hline & IT2 & $\begin{array}{l}\text { When I shop online, the AI virtual customer service as- } \\
\text { sistant can answer my questions in time. }\end{array}$ \\
\hline & IT3 & $\begin{array}{l}\text { When I shop online, the answers of AI virtual customer } \\
\text { service assistant are closely related to my questions. }\end{array}$ \\
\hline & UV1 & $\begin{array}{l}\text { With the support of AI marketing technology, online } \\
\text { shopping can save me more time and cost. }\end{array}$ \\
\hline \multirow{3}{*}{ Utility Value(UV) } & UV2 & $\begin{array}{l}\text { With the support of AI marketing technology, online } \\
\text { shopping can save my shopping price cost more. }\end{array}$ \\
\hline & UV3 & $\begin{array}{l}\text { Shopping on the platform supported by AI marketing } \\
\text { technology improves my shopping efficiency. }\end{array}$ \\
\hline & UV4 & $\begin{array}{l}\text { AI marketing technology to provide me with the choice, } \\
\text { let me feel more practical. }\end{array}$ \\
\hline \multirow{5}{*}{ Hedonic Value(HV) } & UV5 & $\begin{array}{l}\text { With the support of AI marketing technology, I think } \\
\text { shopping is more convenient. }\end{array}$ \\
\hline & HV1 & $\begin{array}{l}\text { With the support of AI marketing technology, online } \\
\text { shopping makes me feel very happy. }\end{array}$ \\
\hline & HV2 & $\begin{array}{l}\text { With the support of AI marketing technology, online } \\
\text { shopping makes me feel very relaxed. }\end{array}$ \\
\hline & HV3 & $\begin{array}{l}\text { With the support of AI marketing technology, online } \\
\text { shopping can arouse my shopping desire. }\end{array}$ \\
\hline & HV4 & $\begin{array}{l}\text { With the support of AI marketing technology, it can } \\
\text { bring me a sense of surprise and curiosity. }\end{array}$ \\
\hline
\end{tabular}


The target e-commerce platform of this study selected the top3 online shopping platforms of China's top 100 e-commerce platforms in 2019: Taobao, Jingdong and Pinduoduo. The respondents are consumers with online shopping experience. In the process of research, the questionnaire is designed through the questionnaire star platform, and consumers fill in the questionnaire online.

688 questionnaires were collected in this study, and those with less than 60 seconds of answer time and those with repeated answers were considered invalid. Finally, 631 valid questionnaires were obtained and the effective rate was $91.7 \%$, which met the statistical requirements that the effective sample size was at least 5 times of the measurement items.

Demographic analysis of valid questionnaires: in terms of gender distribution, $38.99 \%$ of men and $61.01 \%$ of women; in terms of age distribution, $3.96 \%$ are under 20 years old, $38.51 \%$ are between 21 and 30 years old, $45.08 \%$ are between 31 and 40 years old, $8.40 \%$ are between 41 and 50 years old, and $3.33 \%$ are above 51 years old; in terms of educational background, $20.13 \%$ are under bachelor's degree, $54.2 \%$ are under bachelor's degree, and $25.67 \%$ are master's degree or above; In terms of family income, annual disposable income below 100000 accounted for 26.47\%, 100000-200000 accounted for 34.39\%, 200000-300000 accounted for $21.24 \%$, and more than 300000 accounted for $17.9 \%$; in terms of online shopping history, less than 3 years accounted for 6.81\%, 3-6 years of shopping experience accounted for $35.5 \%$, 7-9 years of shopping experience accounted for $28.05 \%$, and more than 10 years accounted for $29.64 \%$; in terms of online shopping frequency, 2-4 times a week accounted for $32.65 \%$, and more than 5 times a day accounted for $5.71 \%$.

\subsection{Data analysis method}

SPSS 23.0 and SPSS test were used to analyze the data. Firstly, the reliability test, validity test and exploratory factor analysis of the sample data of the scale are carried out; Secondly, the confirmatory factor analysis is carried out on the structural equation model to ensure that the data and the model can achieve good fitting; Finally, overall and multi group path coefficient analysis were carried out on the theoretical model.

\section{Analysis of research results}

\subsection{Reliability and validity analysis}

Cronbach'a coefficient was used to test the reliability of the questionnaire and the latent variables formed by multiple measurement items. As shown in Table 2, the Cronbach'a values of all latent variables in this study are between 0.743-0.836, and the combined reliability values are between $0.855-0.877$, which are higher than 0.7 . The Cronbach'a values of the whole sample data reach 0.927 , so it has good reliability for the measurement of variables. In the process of validity analysis, KMO test and Bartlett spherical test were used first and the final measurement data were calculated. The KMO value was 0.944 , greater than 0.9 , which was very suitable for factor analysis; Bartlett spherical test level was significant $(\mathrm{P}<0.001)$, which indicated that the above data were suitable for factor analysis. After analyzation of SPSS25.0, the factor loads of all items on their latent variables were measured by factor analysis. All factor loads were more than 0.7 , and the average variance extraction value (AVE) of each latent variable was more than 0.5 , which indicated that the measurement of variables had good convergence.

Table 2. Analysis of Reliability and Validity

\begin{tabular}{cccccc}
\hline Latent variable & Items & Factor load & Cronbach'a & $\begin{array}{l}\text { Composite } \\
\text { Reliability }\end{array}$ & AVE \\
\hline \multirow{2}{*}{ AC } & AC1 & 0.813 & & & \\
& AC2 & 0.823 & 0.743 & 0.855 & 0.662 \\
AC3 & 0.805 & & & \multirow{2}{*}{0.658} \\
\hline
\end{tabular}




\begin{tabular}{|c|c|c|c|c|c|}
\hline & IS3 & 0.800 & & & \multirow{4}{*}{0.672} \\
\hline \multirow{3}{*}{ IT } & IT1 & 0.836 & \multirow{3}{*}{0.773} & \multirow{3}{*}{0.860} & \\
\hline & IT2 & 0.800 & & & \\
\hline & IT3 & 0.824 & & & \\
\hline \multirow{5}{*}{ UV } & UV1 & 0.785 & \multirow{5}{*}{0.816} & \multirow{5}{*}{0.874} & \multirow{5}{*}{0.581} \\
\hline & UV2 & 0.701 & & & \\
\hline & UV3 & 0.777 & & & \\
\hline & UV4 & 0.766 & & & \\
\hline & UV5 & 0.779 & & & \\
\hline \multirow{5}{*}{$\mathrm{HV}$} & HV1 & 0.748 & \multirow{5}{*}{0.836} & \multirow{5}{*}{0.877} & \multirow{5}{*}{0.588} \\
\hline & HV2 & 0.711 & & & \\
\hline & HV3 & 0.790 & & & \\
\hline & HV4 & 0.788 & & & \\
\hline & HV5 & 0.794 & & & \\
\hline \multirow{4}{*}{ CPI } & CPI1 & 0.759 & \multirow{4}{*}{0.788} & \multirow{4}{*}{0.864} & \multirow{4}{*}{0.615} \\
\hline & CPI2 & 0.809 & & & \\
\hline & CPI3 & 0.832 & & & \\
\hline & CPI4 & 0.733 & & & \\
\hline
\end{tabular}

\subsection{Common method deviation test}

In order to reduce the common method deviation, this study concealed the variable names in the questionnaire design process and adopted the Harman single factor analysis method accepted by most studies. All items in the questionnaire were analyzed by factor analysis without rotation and the highest explained factor variance contribution rate was $38.86 \%$. It can be considered that the common method deviation in this study is not significant.

\subsection{Hypothesis test and conclusion}

In this study, Amos23.0 software was used to construct the structural equation for model fitting. From the fitting test results, the model fitting effect was relatively good, CMIN/DF=3.769, AGFI, NFI, IFI, CFI values were 0.868, 0.867, 0.899, 0.898, RMESA value was 0.066 , which met the recommended standard of model fitting, and were suitable for further path analysis.

The hypothesis test results of the theoretical model were shown in Table 3. The results show that the $\mathrm{P}$ values of all relationships are significant when they are less than 0.001, and the model and path coefficient are shown in Figure 3.

$\mathrm{H} 1 \mathrm{a}$ and $\mathrm{H} 1 \mathrm{~b}$ have passed the significance test, which shows that the accuracy of AI marketing technology experience of online shopping platform is conducive to improving consumers' perceived utilitarian value and hedonic value. With the increase of the accuracy of AI marketing technology, consumers are more likely to perceive the utilitarian value and hedonic value in the process of shopping; H1c and h1d have passed the significance test, which shows that with the insight of AI marketing technology With the increase and deepening of ability, consumers' perception of utilitarian value and hedonic value will increase significantly; h1e and H1f pass the significance test, which shows that the stronger the online interaction of AI marketing technology on online shopping platform, the more conducive it is to increase consumers' perception of utilitarian value and hedonic value. (Table 3)

Both $\mathrm{H} 2 \mathrm{a}$ and $\mathrm{H} 2 \mathrm{~b}$ have pass the significance test. It shows that the perceived utilitarian value and perceived hedonic value brought by AI marketing technology can promote the formation of consumers' purchase intention. The path coefficient of perceived hedonic value (0.605) is higher than that of perceived utilitarian value (0.229), which indicates that perceived hedonic value can promote the formation of consumers' purchase intention more than utilitarian value. (Table 3) 


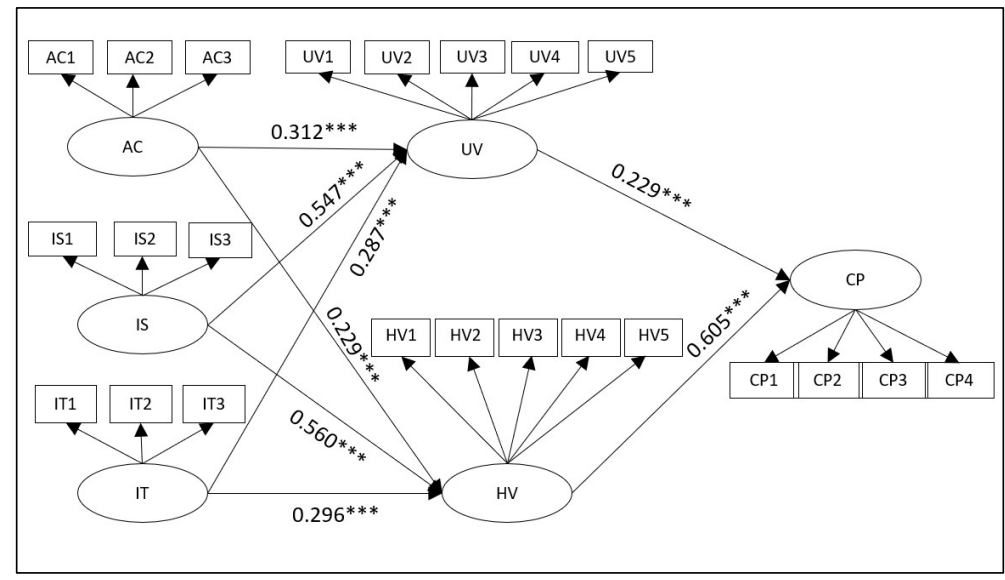

Figure 3 Model and Path Coefficient

Table 3. Results for Hypotheses Verification

\begin{tabular}{ccccccc}
\hline Hypotheses & Path & Estimate & S.E. & C.R. & P & Result \\
\hline H1a & AC $\rightarrow$ UV & 0.312 & 0.041 & 7.636 & $* * *$ & supported \\
H1b & AC $\rightarrow$ HV & 0.229 & 0.045 & 5.106 & $* * *$ & supported \\
H1c & IS $\rightarrow$ UV & 0.547 & 0.049 & 11.233 & $* * *$ & supported \\
H1d & IS $\rightarrow$ HV & 0.560 & 0.054 & 10.304 & $* * *$ & supported \\
H1e & IT $\rightarrow$ UV & 0.287 & 0.032 & 9.073 & $* * *$ & supported \\
H1f & IT $\rightarrow$ HV & 0.296 & 0.037 & 8.095 & $* * *$ & supported \\
H2a & UV $\rightarrow$ CP & 0.229 & 0.062 & 3.693 & $* * *$ & supported \\
H2b & HV $\rightarrow$ CP & 0.605 & 0.064 & 9.429 & $* * *$ & supported \\
\hline
\end{tabular}

Note: ${ }^{* * *}$ represents $\mathrm{P}<0.001$;

4.4 Result analysis of multi group model

Through the analysis of multi group model, it is found that the results of each group are basically consistent with the results of the overall model, and some hypotheses under different conditions don't meet the significance, which reflects the characteristics of consumer value perception and consumer purchase intention under different population characteristics.

According to the demographic characteristics of gender and age, the model test results show that: the male consumer group H2a hypothesis doesn't meet the significance $\left(0.084^{0.439}\right)$, other hypotheses pass the significance test. The result shows that to the group of male consumers AI marketing technology used in online shopping platform to save shopping time, improve shopping efficiency, shopping convenience and other perceived utilitarian value cannot meet the requirements. But perceived hedonic value can promotes the formation of actual purchase intention. (Table 4)

Table 4. Multi-Group Analysis based on Gender and Age

\begin{tabular}{ccccc}
\hline Hypotheses & $\begin{array}{c}\text { Male } \\
(\mathrm{N}=246)\end{array}$ & $\begin{array}{c}\text { Female } \\
(\mathrm{N}=385)\end{array}$ & $\begin{array}{c}\text { Age } \leqslant 30 \\
(\mathrm{~N}=268)\end{array}$ & $\begin{array}{c}\text { Age }>30 \\
(\mathrm{~N}=363)\end{array}$ \\
\hline $\mathrm{H} 1 \mathrm{a}$ & $0.322^{* * *}$ & $0.282^{* * *}$ & $0.374^{* * *}$ & $0.265^{* * *}$ \\
$\mathrm{H} 1 \mathrm{~b}$ & $0.254^{* * *}$ & $0.202^{* * *}$ & $0.215^{*}$ & $0.245^{* * *}$ \\
$\mathrm{H} 1 \mathrm{c}$ & $0.570^{* * *}$ & $0.585^{* *}$ & $0.508^{* * *}$ & $0.640^{* * *}$ \\
$\mathrm{H} 1 \mathrm{~d}$ & $0.662^{* * *}$ & $0.546^{* * *}$ & $0.491^{* * *}$ & $0.650^{* * *}$ \\
$\mathrm{H} 1 \mathrm{e}$ & $0.272^{* * *}$ & $0.271^{* * *}$ & $0.370^{* * *}$ & $0.231^{* * *}$ \\
$\mathrm{H} 1 \mathrm{f}$ & $0.272^{* * *}$ & $0.307^{* * *}$ & $0.351^{* * *}$ & $0.249^{* * *}$ \\
$\mathrm{H} 2 \mathrm{a}$ & $0.084^{0.439}$ & $0.319^{* * *}$ & $0.399^{*}$ & $0.131^{*}$ \\
$\mathrm{H} 2 \mathrm{~b}$ & $0.676^{* * *}$ & $0.543^{* * *}$ & $0.570^{* * *}$ & $0.591^{* * *}$ \\
\hline
\end{tabular}


Note: ${ }^{* *}$ represents $\mathrm{p}<0.001 ;{ }^{* *}$ represents $\mathrm{p}<0.01$; $^{*}$ represents $\mathrm{p}<0.05$

The control variables were divided into three levels: college degree and below, undergraduate degree, graduate degree and above. Conclusions were drawn by fitting the model respectively: (1) The hypothesis $\mathrm{H} 1 \mathrm{~b}\left(0.100^{0.265}\right)$ and $\mathrm{H} 2 \mathrm{a}\left(0.007^{0.938}\right)$ of college degree and below group didn't pass the significance test, which means that the accuracy of AI marketing technology cannot bring hedonic value perception to consumers with lower education background; In the process of online shopping, the perceived hedonic value brought by AI marketing is an important influence factor of purchase intention, but not the perceived utilitarian value; (2) The hypothesis H1f $\left(0.089^{0.118}\right)$ and $\mathrm{H} 2 \mathrm{a}\left(0.14^{0.112}\right)$ of graduate students and above didn't pass the significance test, which indicates that the consumers with high educational background think that the interaction of AI marketing technology will not significantly promote the formation of perceived hedonic value, but the perceived utilitarian value will not promote the formation of purchase intention. The consumers at this level think that the main factors that promote the formation of purchase intention are perceived hedonic value; (3) Other groups all pass the hypothesis test. (Table 5)

The control variables of consumer disposable income are divided into three groups: 0-100000, 100000-200000 and above 200000 .The results show that: (1) The hypothesis H1b $\left(0.053^{0.510}\right)$ and H2a $\left(0.112^{0.221}\right)$ of the group with annual disposable income of $0-100000$ don't pass the significance test, which means that this group of consumers think that the accuracy of AI marketing technology of online shopping platform can't improve their perception of hedonic value, but can only bring the perception of utilitarian value, and the perceived utilitarian value of AI marketing technology cannot significantly promote the formation of purchase intention; (2) The hypothesis H2a $\left(0.291^{0.095}\right)$ of the group with annual disposable income of 100000-200000 did not pass the significance test, indicated that the perceived utilitarian value of online shopping platform, AI technology cannot significantly promote the purchase intention formation of the group who are in the middle income level.(Table 5)

Table 5. Multi-group Analysis based on Education and Disposable income (CHY)

\begin{tabular}{ccccccc}
\hline Hypotheses & $\begin{array}{c}\text { Below } \\
\text { College } \\
(\mathbf{N = 1 2 7})\end{array}$ & $\begin{array}{c}\text { Bachelor } \\
(\mathbf{N}=342)\end{array}$ & $\begin{array}{c}\text { Graduate } \\
\text { student } \\
(\mathbf{N}=162)\end{array}$ & $\begin{array}{c}\mathbf{0 - 1 0 0 0 0 0} \\
(\mathbf{N}=167)\end{array}$ & $\begin{array}{c}\text { 100000- } \\
\mathbf{2 0 0 0 0 0} \\
(\mathbf{N}=\mathbf{2 1 7})\end{array}$ & $\begin{array}{c}>200000 \\
(\mathbf{N}=\mathbf{2 4 7})\end{array}$ \\
\hline $\mathrm{H} 1 \mathrm{a}$ & $0.534^{* * *}$ & $0.198^{* * *}$ & $0.316^{* * *}$ & $0.271^{* * *}$ & $0.358^{* * *}$ & $0.299^{* *}$ \\
$\mathrm{H} 1 \mathrm{~b}$ & $0.100^{0.265}$ & $0.265^{* * *}$ & $0.300^{* * *}$ & $0.053^{0.510}$ & $0.409^{* * *}$ & $0.314^{* *}$ \\
$\mathrm{H} 1 \mathrm{c}$ & $0.418^{* * *}$ & $0.567^{* * *}$ & $0.642^{* *}$ & $0.504^{* * *}$ & $0.502^{* * *}$ & $0.712^{* * *}$ \\
$\mathrm{H} 1 \mathrm{~d}$ & $0.722^{* * *}$ & $0.534^{* * *}$ & $0.517^{* * *}$ & $0.694^{* * *}$ & $0.645^{* * *}$ & $0.577^{* * *}$ \\
$\mathrm{H} 1 \mathrm{e}$ & $0.315^{* * *}$ & $0.375^{* * *}$ & $0.157^{* * *}$ & $0.300^{* * *}$ & $0.299^{* * *}$ & $0.185^{* *}$ \\
$\mathrm{H} 1 \mathrm{f}$ & $0.430^{* * *}$ & $0.422^{* * *}$ & $0.089^{0.118}$ & $0.266^{* * *}$ & $0.223^{* * *}$ & $0.351^{* * *}$ \\
$\mathrm{H} 2 \mathrm{a}$ & $0.007^{0.938}$ & $0.536^{* * *}$ & $0.140^{0.112}$ & $0.112^{0.221}$ & $0.291^{0.095}$ & $0.336^{* *}$ \\
$\mathrm{H} 2 \mathrm{~b}$ & $0.706^{* * *}$ & $0.405^{* * *}$ & $0.593^{* * *}$ & $0.617^{* * *}$ & $0.697^{* * *}$ & $0.394^{* *}$ \\
\hline
\end{tabular}

Note: ${ }^{* * *}$ represents $\mathrm{p}<0.001 ;{ }^{* *}$ represents $\mathrm{p}<0.01$; ${ }^{*}$ represents $\mathrm{p}<0.05$

As the variable online shopping years are divided into three groups: 0-6 years, 7-9 years, and more than 10 years, the online shopping frequency is divided into two groups: Once a day and above, once a day and below. The following conclusions can be drawn by fitting the model: (1) The consumption group with 0-6 years of shopping experience assumes that $\mathrm{H} 2 \mathrm{a}\left(0.182^{0.128}\right)$ doesn't pass the significance test, which indicates that the group thinks that the AI marketing technology of online shopping platform brings about the perception utilitarian value cannot significantly promote the formation of their purchase intention; (2) Consumers with 7-9 years of shopping experience assume that $\mathrm{H} 1 \mathrm{~b}\left(0.171^{0.078}\right)$ and $\mathrm{H} 2 \mathrm{a}\left(0.163^{0.163}\right)$ didn't pass the significance test, indicating that the Group believes that the accuracy of AI marketing technology on online shopping platform is not conducive to the formation of perceived hedonic value, and the perceived utilitarian value brought by AI marketing technology on online shopping platform is not significant;(3) Except for H2a $\left(0.128^{0.092}\right)$, all the other hypotheses of online shopping frequency below once a day pass the significance test, which shows that consumers with low shopping frequency think that the perceived hedonic value rather than the perceived utilitarian value brought by AI technology promotes their purchase intention.

Table 6. Multi-group Analysis based on Online Shopping Experience and Shopping Frequency 


\begin{tabular}{cccccc}
\hline Hypotheses & $\begin{array}{c}\text { 0-6years } \\
(\mathrm{N}=267)\end{array}$ & $\begin{array}{c}\text { 7-9years } \\
(\mathrm{N}=177)\end{array}$ & $\begin{array}{c}\text { above10years } \\
(\mathrm{N}=187)\end{array}$ & $\begin{array}{c}\text { Once a day or } \\
\text { more } \\
(\mathrm{N}=\mathbf{2 2 8})\end{array}$ & $\begin{array}{c}\text { Less than } \\
\text { once a day } \\
(\mathrm{N}=403)\end{array}$ \\
\hline H1a & $0.366^{* * *}$ & $0.516^{* * *}$ & $0.166^{* *}$ & $0.207^{* * *}$ & $0.370^{* * *}$ \\
$\mathrm{H} 1 \mathrm{~b}$ & $0.154^{*}$ & $0.171^{0.078}$ & $0.324^{* * *}$ & $0.204^{* *}$ & $0.273^{* * *}$ \\
$\mathrm{H} 1 \mathrm{c}$ & $0.508^{* * *}$ & $0.650^{* * *}$ & $0.601^{* * *}$ & $0.544^{* * *}$ & $0.579^{* * *}$ \\
$\mathrm{H} 1 \mathrm{~d}$ & $0.666^{* * *}$ & $0.655^{* * *}$ & $0.509^{* * *}$ & $0.466^{* * *}$ & $0.634^{* * *}$ \\
$\mathrm{H} 1 \mathrm{e}$ & $0.422^{* * *}$ & $0.210^{* * *}$ & $0.230^{* * *}$ & $0.295^{* * *}$ & $0.255^{* * *}$ \\
$\mathrm{H} 1 \mathrm{f}$ & $0.444^{* * *}$ & $0.300^{* * *}$ & $0.198^{* * *}$ & $0.355^{* * *}$ & $0.260^{* * *}$ \\
$\mathrm{H} 2 \mathrm{a}$ & $0.182^{0.128}$ & $0.163^{0.163}$ & $0.251^{* *}$ & $0.416^{* * *}$ & 0.128 .092 \\
$\mathrm{H} 2 \mathrm{~b}$ & $0.638^{* * *}$ & $0.678^{* * *}$ & $0.536^{* * *}$ & $0.329^{* * *}$ & $0.734^{* * *}$ \\
\hline
\end{tabular}

\section{Conclusions and Discussion}

\subsection{Research conclusion}

6.1.1 On the whole, the AI marketing technology experience of online shopping platform is conducive to improve consumers' perceived value.

The higher the accuracy of AI marketing technology, the more conducive to enhance consumers' perceived utilitarian value and perceived hedonic value. Combined with the survey results, consumers are most satisfied with the accuracy of text retrieval enabled by AI marketing technology, but limited by image recognition technology and voice recognition technology, the accuracy brought by both will affect the retrieval experience of consumers. The perceived utilitarian value of AI marketing technology improved by accuracy is greater than the perceived hedonic value, which indicates that consumers think that AI marketing technology has higher utility in terms of shopping convenience, time and cost saving, while the perception of hedonic value brought by accuracy is not as strong as the degree of utilitarian value. Only low educated and low-income consumers are limited by disposable income. In the process of online shopping, they pay more attention to the perceived utilitarian value brought by AI marketing technology which are price saving and shopping efficiency, but not the perceived hedonic value. Therefore, in the future, with the upgrade of AI marketing technology, we should pay attention to the characteristics of different income and cognitive groups, optimize the recommendation methods of different groups of products, and ensure that the recommended products are more accurately close to the real needs of consumers with different income levels and cultural levels from the price, performance, quality and other dimensions, so as to promote the formation of shopping intention.

The higher the insight of AI marketing technology of online shopping platform, the more conducive to enhance consumers' perceived utilitarian value and perceived hedonic value. Combined with the results of the questionnaire, consumers' recognition of AI marketing technology insight is higher than its accuracy and interactivity. At the same time, AI marketing technology brings insight experience to online shoppers, which is not only conducive to improving consumers' perceived utilitarian value, but also can promote the pleasure of shopping process through insight, increase the sense of curiosity and curiosity in the consumption process, and stimulate shopping desire and interest. Consumers' purchase intention through perceived hedonic value is stronger than perceived utilitarian value.

6.1.2 The perceived value of online shopping platform AI marketing technology can promote the formation of consumers' purchase intention, and the influence of perceived hedonic value is greater. 
Firstly, perceived utilitarian value and perceived hedonic value play a positive mediating role between AI marketing technology experience and consumers' purchase intention, which indicates that AI marketing technology can promote the formation of purchase intention through the mediating of perceived value. Secondly, the promotion of perceived hedonic value on consumers' purchase intention is greater than that of perceived utilitarian value, which indicates that with the improvement of consumers' income and cultural level and the continuous upgrading of consumption concept, consumers pay more attention to spiritual hedonic in the shopping process. With the popularity of online shopping mode and the continuous iteration of online platform technology, functional requirements such as product selection, shopping efficiency and convenience can be fully realized in the mainstream e-commerce platform. Consumers prefer and rely more on the spiritual experience of stimulating shopping desire, pleasure and relaxation brought by AI technology stimulation in the process of online shopping. AI is good at flexibly changing its recommendation trajectory according to consumer behavior, continuously mining potential demand, and directly stimulating consumers' shopping desire from the sense. The higher the hedonic value in the process of online shopping, the more promote the formation of consumers' purchase intention.

The higher interactivity of AI marketing technology of online shopping platform, the more conducive to the formation of consumers' perceived utilitarian value and perceived hedonic value. Combined with the statistical results of the questionnaire, consumers think that the satisfaction of AI virtual customer service assistant is far lower than that of accuracy and insight, and the interactive performance of AI marketing technology of online shopping platform is the weakest to promote the formation of two kinds of perceived value. It shows that the current consumers generally agree that the AI customer service of online shopping platform can solve the product description, delivery time, logistics information and other conventional problems, but the relatively complex semantics and human-computer interaction, the current AI technology is not enough to meet the needs of consumers' personalized and emotional communication, especially the highly educated group significantly does not agree that interaction can promote the formation of perceived hedonic value.

For different characteristic groups, limited by the total sample size, the results have some differences: men, high and low education level, disposable income less than 200000, less than 10 years of shopping experience, low frequency of online shopping consumers prefer the shopping desire stimulation, shopping process relaxation, pleasure and other hedonic experience brought by AI marketing, while utilitarian value cannot promote the purchase intention of these consumers. This reflects the trend that the consumption concept of the younger consumer groups is changing to hedonic value, and it can also be an important feature reference for AI to use consumer feature portraits for marketing.

\subsection{Management inspiration}

E-commerce platform enterprises should continue to strengthen the investment and empowerment of AI technology in marketing, optimize and upgrade the application of intelligent search, intelligent recommendation and intelligent interaction technology, improve the retrieval accuracy of search engines for different forms of character fields, pictures, voice and images, and strengthen the technical ability of big data retrieval service; Optimize the platform algorithm and strengthen the AI insight ability of the platform in order to create a more accurate and satisfactory interactive environment for consumers, we need to excavate consumer behavior rules, predict consumers' intention prospectively, stimulate consumers' desire for shopping, optimize the relaxation and pleasure experience in the shopping process; Continue to increase the investment in AI interaction technology, break through the existing technical bottleneck of AI customer service natural language learning and understanding, and create a more accurate and satisfactory interaction environment for consumers. 
E-commerce enterprises should pay attention to the technology ability construction of AI and consumers' hedonic psychology, expand the application boundary based on consumers' online shopping behavior. At the same time deepen the combination of machine vision, artificial neural network and other technologies with online shopping scene. While expand the exploration of consumers' eye movement, expression change, reasoning psychological state change, and more accurately grasp the factors that stimulate consumers' perception of hedonic value and ccelerate the formation of consumers' purchase intention.

\subsection{Limitations and Prospects}

This study has certain limitations and needs to be further explored in the exploration of AI marketing in the future. First of all, in order to highlight the core influencing factors, this study only considers the core perceived value of the internal influencing mechanism of consumers as the intermediary influence, but does not consider other internal influencing factors such as perceived risk, flow experience, consumer attitude and other mediating variables that affect consumer behavior; Second, this study only considers the influence differences under the differences of demographic characteristics, but does not consider other factors like the moderating effects of consumer self-construction, preference characteristics, experience and cognitive style. Finally, in the empirical research, only using the questionnaire survey method which online to fill, but unable to deeply analyze the thinking process of consumers and judge the errors caused by different motives. The above directions and deficiencies that need to be further deeply research.

Author Contributions: Conceptualization, YIN Jiwang and QIU Xiaodong; methodology, YIN Jiwang; software, YIN Jiwang; validation, YIN Jiwang.; formal analysis, YIN Jiwang; investigation, YIN Jiwang; data curation, YIN Jiwang; writing - original draft preparation, YIN Jiwang; writingreview and editing, YIN Jiwang; supervision, QIU Xiaodong. All authors have read and agreed to the published version of the manuscript."

Funding: This research was funded by a grant from the Chinese National Funding of Social Science (15AGL002)

Acknowledgments: Thanks to Dr. Qiu for his supervision and guidance. Thanks to my classmates and workmates for their suggestions on the questionnaire and their cooperation in filling in the questionnaire.

Conflicts of Interest: The authors declare no conflict of interest.

\section{References}

1. Sterne J. Artificial intelligence for marketing practical application.1 $1^{\text {st }}$ ed. Tsinghua University Press: Beijing, China,2019;pp. 915.

2. Yi, Y .AI marketing, $1^{\text {st }}$ ed.;China Renmin University Press,Beijing,China,2019;pp.22-35.

3. Xianqing,W.;Shaohui,L. Research on the influence of AI on consumption and shopping experience in the new retail environment-based on the perspective of commercial retail reform and reconstruction of people-goods-yard system. Journal of Commercial Economics 2018,17,5-8.

4. Overgoor,G.;Chica,M. William R. Letting the computers take over: using AI to solve marketing problems. California Management Review 2019,8,1-30.

5. Berg, N.; Kinghts,M. Amazon: How the world's most relentless retailer will continue to revolutionize commerce. CITIC Press Group,2019;pp.167-175.

6. Mehrabian,A.; Russell, J, A. An approach to environmental psychology. Cambridge: MIT Press,1974;pp.62-65.

7. Donovan, R,J.; Rossiter,J,R.Store atmosphere: An environmental psychology approach. Journal of Retailing 1982, 58, 34-57.

8. Eroglu,S,A; Machleit,K,A; Davis,L,M. Atmospheric qualities of online retailing - A conceptual model and implications. Journal of Business Research 2001, 54,177-184.

9. Eroglu,S, A.; Machleit, K. A.;Davis,L, M. Empirical testing of a model of online store atmospherics and shopper responses . Psychology and Marketing 2003, 20,139-150. 
10. Lu,Y. Effects of online store atmosphere on consumer purchase intention. Chongqing University.2009.

11. Floh,A.; Madlberger,M. The role of atmospheric cues in online impulse-buying behavior. Electronic Commerce Research and Applications 2013, 12, 425-439.

12. Carlota,L. R.; Alarcón-del-Amo María-del-Carmen; Gómez-Borja Miguel-ángel . Analyzing the user behavior toward electronic commerce stimuli. Frontiers in Behavioral Neuroscience 2016, 10, 1-18.

13. Sanjeev,P, T. S. V; Chandan,P.Effects of online shopping values and website cues on purchase behavior: A study using S-O-R framework. The Journal for Decision Makers 2017, 42, 1-18.

14. Peijia,Z.Research on the influence mechanism of online return policy looseness on consumers' purchase intention based on SO-R theory. Consumer Economics 2017,1,85-91.

15. Fikri,A.; Nurmalina,R.;Najib,M.The determinants of online vegetables/fruits repurchase intention: stimulus-organism-response model and theory of planned behaviour . European Scientific Journal 2019,15,147-167.

16. Yun,Z. S.;Good,L.K. Developing customer loyalty from e-tail store image attributes . Journal of Service Theory \& Practice 2007, 17: 4-22.

17. Shen,J.;,Hongxia,Z. B2C online store image, consumer perception and purchase behavior. Research on Financial and Economic Issues 2013,10,116-122.

18. Xiling,C.; Lai,V.S.E-loyalty to online auction websites: A stimulus-organism-response model, Doctoral Dissertation, Hong Kong Shue Yan University,2013.

19. Gloria, E.;Ichalkaranje,N.;Lakhmi,C. Intelligent Decision Making: An AI-Based Approach, 1st ed. Springer :Berlin Heidelberg, 2008;pp,29-38.

20. Yanbing,Z.; Wei,L.; Jiayu,Z.Marketing research of AI: Prospect and challenges. Management Review 2019, 32, 75-86.

21. Kunar,V.; Raian,B.;Aian,B.;Venkatesan,V.;Lecinski,J. Understanding the Role of Artificial Intelligence in Personalized Engagement Marketing .California Management Review 2019,8,1-21.

22. Jordan,M,I,;Ordan,M,I; Mitchell,T,M. Machine learning: Trends, perspectives, and prospects . Science 2015, 349,255-260.

23. Minghui,Q.;Zhixuan,X.A study of dynamic recognition of consumer brand decision-making preference based on machine learning method. Nankai Business Review 2019, 22,66-76.

24. Zixing,C.; Guangyou,X.Artificial intelligent and application. Tsinghua University Press: Beijing,China,1996;pp.45-62.

25. Yang,Y.;Sheng,L.;Yiwei,L.;jianmin,J. Big data marketing: Review and prospect.Systems Engineering-Theory\&Practice 2020,40, $2150-2158$.

26. Minghui,H.;,Rust,R.T. A strategic framework for artificial intelligence in marketing. Journal of the Academy of Marketing Science 2020, 8,1-21.

27. Chung,T.S.; Wedel,M.; Rust,R.T.Adaptive personalization using social networks. Journal of the Academy of Marketing Science 2016,44, 66-87.

28. Sigen,S.;Linyan,F. Consumers' demand for dual values and retail marketing innovation from new economic sociology perspective. Journal of Beijing Technology and Business University ( Social Sciences)2019,34,1-11.

29. Junjun,F.; Feng,T.; Yi,D. ;Zhengjie,L.;Guozhong,D.Thoughts on humancomputer interaction in the age of artificial intelligence . Scientia Sinica(Informationis) 2018,48,361-375.

30. Zeithaml,V.A.Consumer perceptions of price, quality, and value: A means-end model and synthesis of evidence. Mark 1988, $52,2-22$.

31. Woodruff,R,B.Customer value: The next source for competitive advantage. Journal of the Academy of Marketing Science 1997,25, 139-153.

32. Sirdeshmukh,D.; Singh,J.; Sabol,B. Consumer trust, value and loyalty in relational exchanges. Journal of Marketing 2002,66, 15-37.

33. Overby,J.W. ;Lee, E. J. The effects of utilitarian and hedonic online shopping value on consumer preference and intentions .Journal of Business Research 2006, 59,1150-1166.

34. Holbrook,M.B. Consumer value: A framework for analysis and research,1st ed.; Psychology Press:U.S. 1999:pp.29-45.

35. Fazal-e-hasan,S.M.;Ahmadi,H. Mortimer,G. Grimmer,M.;Kelly.L. Examining the role of consumer hope in explaining the impact of perceived brand value on customer-brand relationship outcomes in an online retailing environment. Journal of Retailing and Consumer Services 2018,41: 101-111.

36. Zhang, J. Q.; Dixit,A.; Friedmann,R.;Riedmann,R.Customer loyalty and lifetime value: An empirical investigation of consumer packaged goods. Journal of Marketing Theory and Practice 2010,18:127-140.

37. Sweeney,J. C.; Soutar,G.N. Consumer perceived value: The development of a multiple item scale. Journal of Retailing 2001,77, 203-220.

38. Davis,F. D.; Bagozzi,R.P.;Warshaw.P.R. User acceptance of computer technology: A comparison of two theoretical models . Management Science 1989, 35,982-1003.

39. Davis,F.D. User acceptance of information technology: system characteristics, user perceptions and behavioral impacts . International Journal of Man-Machine Studies 1993,38, 475-487.

40. Moon,J.W. Kim,Y.G. Extending the TAM for a world-wide-web context. Information \&Management 2001,38,217-230.

41. Hengli, Y.; Chenliang,L. Why do people stick to Facebook web site? A value theory-based view. Information Technology \& People 2014,27,21-37.

42. Tanming,C.A study on selection intention of consumers' online shopping channel based on SOR theory: official websites and third party flagship stores as examples. Beijing University of Posts and Telecommunications, Beijing,2018-03-09. 
43. Ahn,S.J.; Lee, S. H. The Effect of Consumers' Perceived Value on Acceptance of an Internet-Only Bank Service. Sustainability $2019,11,4599$.

44. I Gusti N.M.W.A.;Tjokorda, G.R.S.The role of perceived value mediate the effect of utilitarian and hedonic shopping value on intent to online repurchase . International Journal of Management and Commerce Innovations 2019,6,1232-1242.

45. Rosenberg,D. How marketers can start integrating AI in their work. Harvard Business Review Digital Articals 2018,5,2-5.

46. Jan, K.; Jeannette,P.;Emily T.Artificial intelligence in advertising . Journal of Advertising Research 2018,9:263-267.

47. Aakash,S.; Panchal,N. Object detection using deep learning and artificial intelligence in E-Commerce. IRE Journals 2019, 2,3740.

48. Liye,M.; Baohong,S.Machine learning and AI in marketing - Connecting computing power to human insights. International Journal of Research in Marketing 2020, 37,481-504.

49. Xi,L.;Ying,W.;Yingying,L. The mediating effect of perceived value between product information push and consumer purchase behavior-Multiple intermediary analysis based on bootstrap method. Mordern Business 2019,09,41-43.

50. Guerra,A.Millennial consumption values in artificial intelligence: An exploratory study of millennial consumer values in artificial intelligence. Jönköping University, Sweden, 2018.

51. Batra,R.Ahtola,O.T. Measuring the hedonic and utilitarian sources of consumer attitudes. Marketing Letters 1990, 2,159-170.

52. Zhu, H. Y.;Wang, Q. ; Yan,L.G. Are consumers what they consume? Linking lifestyle segmentation to product attributes: An exploratory study of the Chinese mobile phone market. Journal of Marketing Management 2009, 25,295-314.

53. Man,C.;Xinguo,Z.;Feng.W. Impact of attributes inconsistency of online review on product sales. East China Economic Management 2015,29,147-153.

54. Fiore,A.M.; Kim,J. An intergrative framework capturing experiential and utilitarian shopping experience. International Journal of Retail \&Distribution Management 2013, 35, 421-442.

55. Xiaomin,L.; Wei,W.; Yuwen,S.;Chao Z. Consumer shopping experience research based on artificial intelligence. Modern Information Technology 2019,3, 153-155.

56. Carlota,L. R.; Alarcón-del-Amo María-del-Carmen; Gómez-Borja Miguel-ángel. Analyzing the user behavior toward electronic commerce stimuli . Frontiers in Behavioral Neuroscience 2016, 10,1-18.

57. Shen, J.;Hongxia,Z.; Lei,M. Research on online interaction and impulsive buying behavior of B2C online shopping. Inquiry Into Economic Issues 2014,5,64-73. 